\title{
Longitudinal changes in sports activity from pre-diagnosis to first five years post- diagnosis: a prospective Chinese breast cancer cohort study
}

Yuan-Yuan Lei', Suzanne C. Ho ${ }^{2}$, Carol Kwok ${ }^{3}$, Ashley Cheng ${ }^{3}$, Ka Li Cheung ${ }^{1}$, Roselle Lee ${ }^{1}$ and Winnie Yeo ${ }^{1,4^{*}}$ (D)

\begin{abstract}
Background: To compare change in level of physical activity between pre-and post- diagnosis of breast cancer in Chinese women.

Methods: Based on an on-going prospective study consisting of a sample of Chinese women with breast cancer, a validated modified Chinese Baecke questionnaire was used to measure physical activity at baseline (12 months before cancer diagnosis), 18-, 36- and 60-months after diagnosis (over the previous 12 months before each interview).

Results: In our cohort of 1462 Chinese women with a mean age of 52 years, the mean level of physical activity at postdiagnosis was 9.6 metabolic equivalent of task (MET)-hours/week, which was significantly higher than that at prediagnosis with mean level of 5.9 MET-hours/week $(P<0.001)$. The mean levels of physical activity at 18-, 36- and 60months follow-up were 9.9, 9.8 and 9.3 MET-hours/week, respectively. There was no significant difference between any two of the three follow-ups at post-diagnosis. The proportions of participant who met World Cancer Research Fund/ American Institute for Cancer Research (WCRF/AICR) recommendation before and after cancer diagnosis were both low, being 20.7 and $35.1 \%$, respectively. Compared to pre-diagnosis, most of the patients improved or had no change on level of physical activity at post-diagnosis, with the respective proportion being 48.2 and $43.8 \%$.

Conclusions: Adherence to current lifestyle recommendation for cancer survivors, Chinese women with breast cancer significantly increased level of physical activity level after cancer diagnosis, and such improvement was sustained to 5 years post-diagnosis. The proportion of patients who met the exercise recommendation for cancer survivors was still low. Encouraging patients on the importance of durable high level of physical activity in breast cancer survivorship is warranted.
\end{abstract}

Keywords: Breast cancer, Exercise, Physical activity, Pre- and post-diagnosis, Chinese women

\footnotetext{
* Correspondence: winnieyeo@cuhk.edu.hk

'Department of Clinical Oncology, Prince of Wales Hospital, the Chinese University of Hong Kong, Shatin, New Territories, Hong Kong SAR, China ${ }^{4}$ Hong Kong Cancer Institute, State Key Laboratory in Oncology in South China, Faculty of Medicine, the Chinese University of Hong Kong, New Territories, Hong Kong SAR, China

Full list of author information is available at the end of the article
}

(C) The Author(s). 2020 Open Access This article is licensed under a Creative Commons Attribution 4.0 International License, which permits use, sharing, adaptation, distribution and reproduction in any medium or format, as long as you give appropriate credit to the original author(s) and the source, provide a link to the Creative Commons licence, and indicate if changes were made. The images or other third party material in this article are included in the article's Creative Commons licence, unless indicated otherwise in a credit line to the material. If material is not included in the article's Creative Commons licence and your intended use is not permitted by statutory regulation or exceeds the permitted use, you will need to obtain permission directly from the copyright holder. To view a copy of this licence, visit http://creativecommons.org/licenses/by/4.0/ The Creative Commons Public Domain Dedication waiver (http://creativecommons.org/publicdomain/zero/1.0/) applies to the data made available in this article, unless otherwise stated in a credit line to the data. 


\section{Background}

In the United States, breast cancer is the most common cancer among females, accounting for $30 \%$ of all new cancer diagnoses in women [1]. In Hong Kong, breast cancer is also the leading cancer, and more than $80 \%$ of newly diagnosed patients have early stage breast cancer [2]. Surgical treatment is the major maneuver in the management of early stage patients. However, such procedure may lead to breast cancer related lymphedema (BCRL), axillary web syndrome (AWS) and cancer-related fatigue. It has been reported that BCRL involves more than $25 \%$ of breast cancer survivors, $[3,4]$ while axillary web syndrome (AWS) after axillary lymph node dissection affects in 6 to $85.4 \%$ $[5,6]$. Cancer-related fatigue is a common disabling conditions in breast cancer survivors [7]. It has been estimated that approximately one-third of cancer survivors have clinically significant fatigue up to 6 years following treatment [8]. Breast cancer survivorship care has aroused increasing attention in recent years, and the management of the above-mentioned complications are topics of concern in the rehabilitation field. The beneficial effects of physical activity on cancer related complications have been supported by strong evidence. A systematic review which included 29 studies suggested that resistance exercise could potentially alleviate BCRL [9]. Two meta-analyses including high quality studies have shown that supervised aerobic exercise was effective in improving cancer-related fatigue among breast cancer survivors [10,11].

Current guidelines recommended breast cancer survivors to engage in regular physical activity, aiming for at least $150 \mathrm{~min}$ of moderate or $75 \mathrm{~min}$ of vigorous aerobic exercise per week [12-14]. However, studies in the US have shown that less than half of breast cancer survivors (37-48\%) met the exercise recommendations [15, 16]. The diagnosis of cancer has been considered as a "teachable moment", when individuals could be motivated to make positive lifestyle changes, including increasing physical activity [17, 18]. Hence, the assessment of exercise habits among cancer survivors at the time of diagnosis and thereafter could be of importance. Healthcare providers many utilize this teachable moment as a chance to educate patients to undergo some lifestyle interventions.

A number of studies have investigated physical activity levels in breast cancer survivors during an immediate period, about 1 year after diagnosis [19-24]. Overall, these studies reported that the level of physical activity was reduced during the immediate period post-diagnosis. Only one prospective study conducted in the US among breast cancer patients has reported the changes of physical activity over a more protracted period, from 2 year before diagnosis to 30-months after diagnosis [25]. Up to now, no study has reported the changes of physical activity before and after breast cancer diagnosis among Asian women including Chinese.
The primary aim of this present study was to compare the changes in level of physical activity from 1 year before diagnosis to 5 years after diagnosis using data from an ongoing prospective cohort of Chinese women with early stage breast cancer. This study also examined the associations between socio-demographic, clinical and lifestyle factors with changes in level of physical activity before and after cancer diagnosis. The hypothesis of the present study was that breast cancer patients would change their level of physical activity after breast cancer diagnosis, and several socio-demographic, clinical and lifestyle factors may be associated with such changes.

\section{Methods}

\section{Study cohort}

The present study was based on a prospective cohort study titled "The Hong Kong NTEC-KWC Breast Cancer Survival Study (HKNKBCSS)", which was designed to evaluate whether dietary phytoestrogens and other lifestyle factors affect breast cancer patients' survival outcome [26]. This study recruited participants at two regional public cancer centers (New Territories East and Kowloon West) in Hong Kong. Consecutive breast cancer patients attending two regional cancer centers in Hong Kong, who were potential eligible participators, were invited to participate in this project. All eligible women should have confirmed, newly diagnosed (defined as having diagnosed within 12 months before study entry), stage 0-III breast cancer [27]. Patients who had prior history of breast or other cancers were ineligible. The study was approved by the Joint CUHK-NTEC Clinical Research Ethics Committee and the KWC Research Ethics Committee of the Chinese University of Hong Kong and the Hong Kong Hospital Authority.

In total, 1462 consented patients enrolled in this study between January 2011 and February 2014. Enrolled patients were interviewed at baseline (T0; within 12 month of breast cancer diagnosis), 18 months (T1; conducted between 12 and 24 months after diagnosis), 36 months (T2; conducted between 30 and 42 months) and 60 months (T3; conducted between 54 and 66 months) after breast cancer diagnosis. The four interviews used similar questionnaires to collect data. As of January 2019, the 60-months follow-up interview has been completed.

\section{Data collection}

Trained interviewers carried out the baseline and followup assessments. At baseline, detailed personal data was collected using standardized questionnaire, which included socio-demographic characteristics such as age at diagnosis, education level, household income, marital status; menopausal status; medical history including diabetes, cardiovascular diseases; lifestyle factors including dietary intake, physical activity, smoking, drinking and supplement use. Height and weight was measured by standard 
protocol, and body mass index (BMI) was categorized as following: underweight $<18.5 \mathrm{~kg} / \mathrm{m}^{2}$, normal $18.5-22.9$ $\mathrm{kg} / \mathrm{m}^{2}$, overweight $23-24.9 \mathrm{~kg} / \mathrm{m}^{2}$, obese $\geq 25 \mathrm{~kg} / \mathrm{m}^{2}$ [28]. At T1, T2 and T3, patients were asked to complete similar questionnaires for collecting dietary intake and physical activity data. Medical records were retrieved for patients' clinical characteristics and anti-cancer treatment.

\section{Physical activity measurements}

Patients reported physical activity habits in the previous year before cancer diagnosis at T0 assessment. Subsequently, patients recalled habitual physical activity over the previous year during interviews at $\mathrm{T} 1, \mathrm{~T} 2$ and $\mathrm{T} 3$ assessment. The mean value at $\mathrm{T} 1, \mathrm{~T} 2$ and $\mathrm{T} 3$ were defined as overall level of physical activity at post-diagnosis.

Physical activity was measured by a validated modified Chinese Baecke questionnaire (Supplementary Table 1), which consisted of physical activity at work, in doing housework, at leisure time (time excluding working and playing sports or exercise) and in doing sports [29]. This study only analyzed physical activity in doing sports for two reasons; firstly, WCRF /AICR recommendations have recommended on sports activity; secondly, data from such an approach would also be more comparable with other studies which have mostly been based on sports and exercises. In each assessment, the subjects who did sport or exercise were asked to specify the activities that they did categorically (up to 2 self-reported sport activities), and the number of hours per week and months of the year they did the activity was recorded. The scores of metabolic equivalent of task (MET)-hours per week was calculated by multiplying the corresponding MET value of the activity by the time (hours per week) engaged in this activity [30]. The MET code for each sport was based on the values in the Ainsworth compendium of physical activity [30]. Summing the score of MET-hours per week of each activity provides the total level of physical activity.

The American Cancer Society (ACS) and World Cancer Research Fund/American Institute for Cancer Research (WCRF/AICR) recommendations for cancer survivors both suggest that individual subject should "be moderately physically active, equivalent to brisk walking, for at least $30 \mathrm{mi}-$ nutes every day." [13, 14] This recommendation could be operationalized as engaged in moderate or fast walking and/or other moderate or strenuous activity for an average of $30 \mathrm{~min}$ per day, for at least 5 days per week. For instance, the scores of MET-hours per week for moderate or fast walking, $30 \mathrm{~min}$ per day, 5 days per week was 10 (calculated as follow: $4.0 \mathrm{METs} /$ hour * $0.5 \mathrm{~h} /$ day * 5 days/week). According to the level of sports activity, patients were categorized into 3 groups as follow: no exercise (0 MET-hours/ week), low-exercise-level (<10 MET-hours/week) and high-exercise-level ( $\geq 10$ MET-hours/week). Patients who belonged to high-exercise-level group were those who met the exercise recommendations for both healthy adults [31] and cancer survivors $[13,14]$..

The individual change of physical activity between prediagnosis (level at T0) and post-diagnosis (mean level at T1, T2 and T3) was classified into three groups: improved (moved from no exercise to low-exercise-level group or from low-exercise-level to high-exercise-level group), no change (kept in the same level of exercise group) and declined (moved from low/high-exercise-level to no exercise group or from high-exercise-level to low-exercise-level group). The absolute change of physical activity between pre-diagnosis and post-diagnosis was calculated by having "the mean level of MET-hours/week at T1, T2 and T3" minus "the level of MET-hours/week at T0".

\section{Statistical analysis}

The HKNKBCSS was primarily designed to evaluate soy intake and breast cancer prognosis. Based on the assumption that the 5-year mortality rate in the nonexposed or low intake is $20 \%$ and the hazard ratio of mortality of 0.7 among the high soy intake relative to the low intake group, [32] this study have recruited 1462 cases and met the target sample size of 1350 to detect the hazard ratio of 0.7 at $5 \%$ level of significance and $80 \%$ power. During each follow-up, those who have completed the baseline data collection and are free of recurrence at the time of follow-up were invited. Patients who lost one of the follow-ups could also join the next follow-up study. All enrolled patients were actively followed-up, and their recurrence and survival statuses were collected yearly by reviewing medical records or asking patients through telephone call.

The difference in physical activity between pre- and post-diagnosis (mean level at T1, T2 and T3) were examined by paired two-sample t-test. Similar analysis was also conducted to detect difference at any two time-points between T1, T2 and T3 post-diagnosis. Chi-square test was used to compare the frequency of patients who changed from no or low-exercise level to high-exercise level after diagnosis by socio-demographic, clinical and lifestyle factors. Multivariate logistic regression model was used to investigate the odds ratio of such change by socio-demographic, clinical and lifestyle factors. The independent two-sample t-test or one-way ANOVA was used to compare the absolute change of physical activity between pre and post-diagnosis by socio-demographic, clinical and lifestyle factors. Multivariate linear regression model was used to investigate the association of physical activity change between pre- and postdiagnosis with socio-demographic, clinical and lifestyle factors. All analyses were performed using SPSS 21.0; and $P$ value $<0.05$ at two-sided analysis were considered statistically significant. 


\section{Results}

\section{Participants' characteristics}

In total, 1462 patients completed baseline interview and enrolled into the study; 1310 (89.6\%), 1162 (79.5\%) and $1173(80.2 \%)$ participants completed the 18, 36 and 60months follow-up interviews respectively. Among 1462 enrolled patients, 1019 patients completed all four assessments (T0, T1, T2 and T3) and were included in the present analysis (Fig. 1). Those who did not complete all follow-ups were excluded. Patients who completed all follow-ups at the four time-points showed similar baseline characteristics with the whole cohort.

The baseline demographic and clinical characteristics of patients included in this analysis are provided in Table 1. The mean age at diagnosis was 52 years. Sixty-two percent had no comorbidity. Nearly half of the patients (47\%) were post-menopausal at diagnosis. Obesity was observed in $28 \%$ of patients. Thirty-seven percent belonged to AJCC stage 0I, $46 \%$ stage II and $17 \%$ stage III. ER, PR and HER2 positivity were presented in 75,59 and $17 \%$ of the patients. All patients in this analysis have completed breast cancer surgery. Majority of patients had received adjuvant chemotherapy, radiotherapy and endocrine therapy, with the corresponding figure being 76.0, 70.8 and 76.3\%, respectively. At baseline, only a small group of patients were current smokers or drinkers, at 1.1 and $1.5 \%$, respectively.

\section{Comparison of physical activity between pre- and post- diagnosis}

The mean levels of physical activity at T0 (pre-diagnosis), T1, T2 and T3 were 5.9, 9.9, 9.8 and 9,3 MET-hours/week, respectively. The overall level of physical activity at postdiagnosis was significantly higher than that at prediagnosis, with mean values of 9.6 vs 5.9 MET-hours/week respectively, $P<0.001$ (Table 2 ). When comparing between T1 and T2, T1 and T3 as well as T2 and T3, there was no significant difference between any two follow-ups at post-diagnosis $(P>0.05$, each). The proportions of participants who never did exercise at pre- and post-diagnosis were 46.4 and $10.9 \%$, respectively. However, for those did exercise, the proportions of participants who met the exercise recommendation of WCRF/AICR were relatively low; the figures increased from $20.7 \%$ at pre-diagnosis to $35.1 \%$ post-diagnosis $(P<0.001)$.

\section{Change in level of physical activity between pre- and post-diagnosis in individual patient}

The changes of physical activity between pre- and postdiagnosis in individual patient are shown in supplementary Table 2. Compared to pre-diagnosis, most of the patients improved or had no change in level of physical activity at post-diagnosis, with the respective proportions being 48.2 and $43.8 \%$, respectively. Only $8.0 \%$ of the patients had their level of physical activity declined at post-diagnosis.

In total, $20.7 \%$ of patients changed from no or low to high level of physical activity after diagnosis. The proportions patients with such positive change by sociodemographic, clinical and lifestyle factors are presented in Table 3. Univariate analysis showed that patients with the following characteristics are more likely to make such positive changes: patients who were aged $\geq 40$ years (compared to those who were aged < 40 years), nonobese (compared to obese), stage II-III (compared to stage $0-\mathrm{I}$ ), and having received adjuvant chemotherapy (compared to no chemotherapy).

Multivariate logistic regression model was used to investigate potential characteristics which could predict higher likelihood of such positive changes. The variables entered into the model were those with $P<0.1$ in the univariate analysis, which included age at diagnosis, marital status, menopausal status, BMI at diagnosis, AJCC stage and chemotherapy. The results of multivariate analysis are presented in supplementary Table 3. Compared to patients who were aged $<40$ years, those who were aged from 40 to 59 years were more likely to make such positive change [age group 40-49 years and 50-59 years: odds ratio $(\mathrm{OR})=$ 2.7, 95\%CI: $1.3 \sim 5.8, P=0.008 ; \mathrm{OR}=3.2,95 \% \mathrm{CI}: 1.5 \sim$ $7.2, P=0.004$, respectively. Patients who were obese at diagnosis were unlikely to make such change after diagnosis compared to those who were underweight $(\mathrm{OR}=0.4$, 95\%CI: $0.2 \sim 1.0, P=0.042$ ).

\section{Absolute changes of physical activity between pre- and post-diagnosis by socio-demographic, clinical and lifestyle factors}

The absolute changes in level of physical activity between pre- and post-diagnosis by socio-demographic, clinical and lifestyle factors were presented in Table 4. Compared to pre-diagnosis, the level of physical activity increased by 2.2 MET-hours/week at post-diagnosis. Univariate analysis showed that higher increase in physical activity was observed among breast cancer patients aged between 40 and 59 years (compared to those who were aged $\geq 60$ years), had a partner (married or cohabitating), not working (compared to full time or part-time) and had no comorbidity (compared to patients who had 1 or more comorbidities).

Multivariate linear regression model was used to investigate the association between absolute changes in level of physical activity and socio-demographic, clinical and lifestyle factors. The variables entered into the model were those with $P<0.1$ in the univariate analysis, which included age at diagnosis, marital status, household income, employment status, BMI at diagnosis and number of comorbidities. The results are presented in supplementary Table 4. Compared to patients who had a partner (married or cohabitating), those who were single 


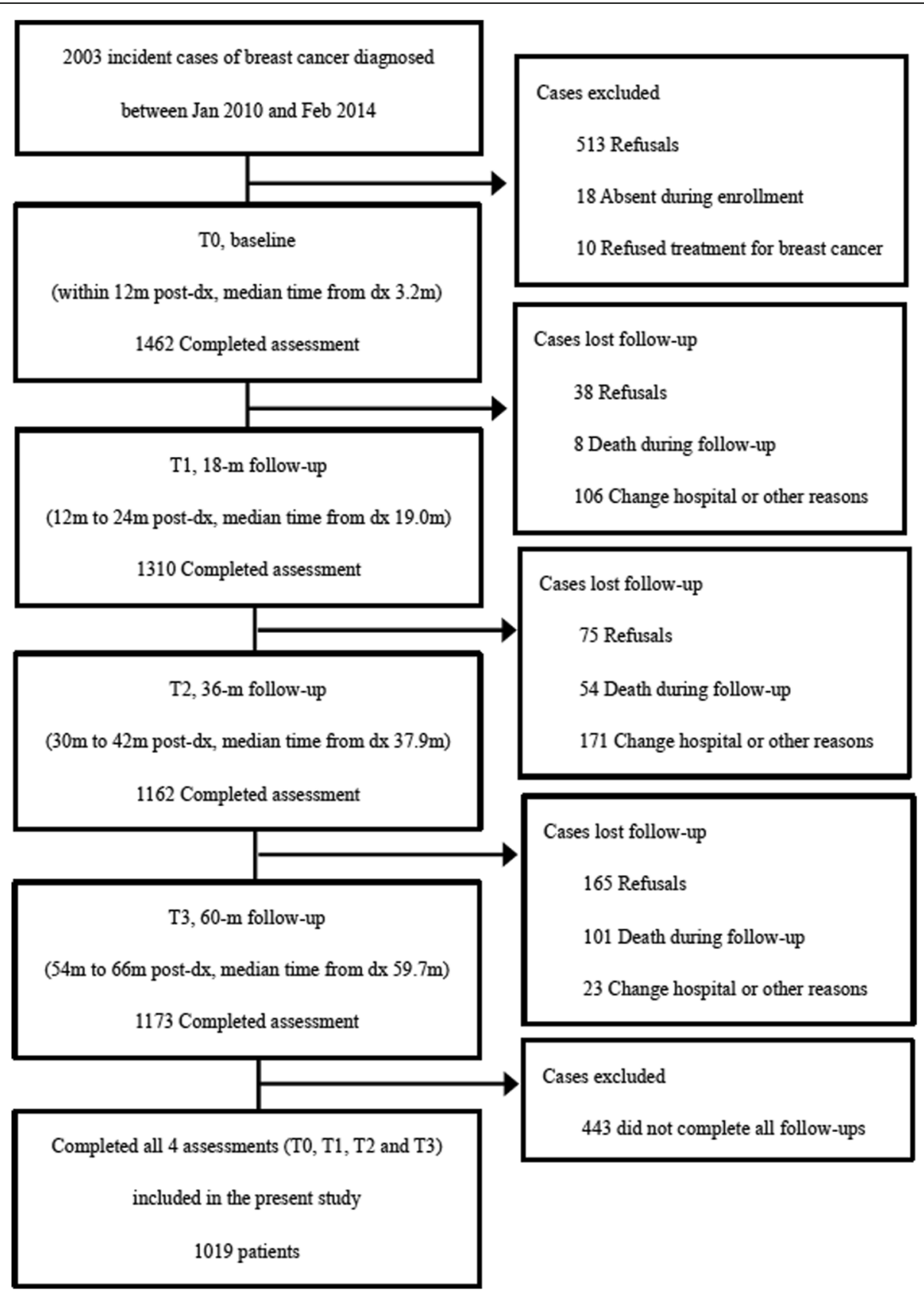

Fig. 1 Study flow chart. Abbreviations: m, month; dx, diagnosis

(unmarried, divorced or widowed) had lower increase in level of physical activity between pre and postdiagnosis $(\beta=-2.0,95 \% \mathrm{CI}:-3.7 \sim-0.3, \quad P=0.021)$. Patients who were not working at baseline showed more increase in level of physical activity after diagnosis compared to those in full-time job $(\beta=2.7$, 95\%CI: $0.9 \sim 4.5, P=0.002)$. Patients with one comorbidity at baseline showed lower increase in level of physical activity after diagnosis compared with those who had no comorbidity $(\beta=-2.8,95 \% \mathrm{CI}$ : $-4.7 \sim$ $1.0, P=0.002)$.

\section{Discussion}

This is the first prospective cohort study that compared the level of physical activity among Chinese breast cancer survivors from 1 year before cancer diagnosis to 5 years after diagnosis. Compared to pre-diagnosis, patients significantly increased their level of physical activity at 18-months post-diagnosis, and the enhanced level of physical activity was well-sustained at 36-months and 60 -months post-diagnosis. When individual change in physical activity was assessed, the majority of patients improved or had no change in their level of physical 
Table 1 Baseline socio-demographic and clinical characteristics of patients included in this study $(n=1019)$

\begin{tabular}{|c|c|c|}
\hline Characteristics & Number of patients & Frequency, \% \\
\hline Age, mean $\pm S D$, year & $52.1 \pm 8.8$ & \\
\hline \multicolumn{3}{|l|}{ Education level } \\
\hline High school or below & 868 & 85.2 \\
\hline Collage or above & 151 & 14.8 \\
\hline \multicolumn{3}{|l|}{ Marital status } \\
\hline Married or cohabitating & 728 & 71.4 \\
\hline $\begin{array}{l}\text { Unmarried or divorced } \\
\text { or widowed }\end{array}$ & 291 & 28.6 \\
\hline \multicolumn{3}{|c|}{ Household income (HKD/month) } \\
\hline$<15,000$ & 463 & 45.4 \\
\hline $15,000-30,000$ & 326 & 32.0 \\
\hline $30,000-50,000$ & 151 & 14.8 \\
\hline$\geq 50,000$ & 79 & 7.8 \\
\hline \multicolumn{3}{|l|}{ Employment status } \\
\hline Full time & 378 & 37.1 \\
\hline Part time & 129 & 12.7 \\
\hline Not working & 512 & 50.2 \\
\hline \multicolumn{3}{|l|}{ Menopausal status } \\
\hline Pre-menopausal & 539 & 52.9 \\
\hline Post-menopausal & 480 & 47.1 \\
\hline \multicolumn{3}{|l|}{ BMI at diagnosis, $\mathrm{kg} / \mathrm{m}^{2}$} \\
\hline Underweight (<18.5) & 37 & 3.6 \\
\hline Normal (18.5-22.9) & 488 & 47.9 \\
\hline Overweight (23-24.9) & 209 & 20.5 \\
\hline Obese ( $\geq 25)$ & 285 & 28.0 \\
\hline \multicolumn{3}{|l|}{ Number of comorbidities } \\
\hline None & 629 & 61.7 \\
\hline 1 & 259 & 25.4 \\
\hline 2 & 101 & 9.9 \\
\hline$\geq 3$ & 30 & 2.9 \\
\hline \multicolumn{3}{|l|}{ AJCC stage at diagnosis } \\
\hline $0-1$ & 375 & 36.9 \\
\hline$\|$ & 471 & 46.2 \\
\hline III & 169 & 16.6 \\
\hline Missing & 4 & 0.4 \\
\hline \multicolumn{3}{|l|}{ Histology } \\
\hline IDC & 858 & 84.2 \\
\hline ILC & 31 & 3.0 \\
\hline DCIS & 56 & 5.5 \\
\hline Others & 74 & 7.3 \\
\hline \multicolumn{3}{|l|}{ ER status } \\
\hline Positive & 763 & 74.9 \\
\hline Negative & 233 & 22.9 \\
\hline Missing & 23 & 2.3 \\
\hline
\end{tabular}

Table 1 Baseline socio-demographic and clinical characteristics of patients included in this study $(n=1019)$ (Continued)

\begin{tabular}{|c|c|c|}
\hline Characteristics & Number of patients & Frequency, \% \\
\hline \multicolumn{3}{|l|}{ PR status } \\
\hline Positive & 598 & 58.7 \\
\hline Negative & 395 & 38.8 \\
\hline Missing & 26 & 2.6 \\
\hline \multicolumn{3}{|l|}{ HER 2 status } \\
\hline Positive & 274 & 26.9 \\
\hline Negative & 686 & 67.3 \\
\hline Missing & 59 & 5.8 \\
\hline \multicolumn{3}{|l|}{ Surgery } \\
\hline Mastectomy & 628 & 61.6 \\
\hline Conservation & 391 & 38.4 \\
\hline \multicolumn{3}{|l|}{ Chemotherapy } \\
\hline Yes & 774 & 76.0 \\
\hline No & 245 & 24.0 \\
\hline \multicolumn{3}{|l|}{ Radiotherapy } \\
\hline Yes & 721 & 70.8 \\
\hline No & 298 & 29.2 \\
\hline \multicolumn{3}{|c|}{ Endocrine therapy } \\
\hline Yes & 777 & 76.3 \\
\hline No & 242 & 23.7 \\
\hline \multicolumn{3}{|l|}{ Smoking status } \\
\hline Yes & 11 & 1.1 \\
\hline No & 1008 & 98.9 \\
\hline \multicolumn{3}{|l|}{ Drinking status } \\
\hline Yes & 15 & 1.5 \\
\hline No & 1004 & 98.5 \\
\hline
\end{tabular}

Abbreviations: $S D$ standard deviation, $H K D$ Hong Kong dollars, $B M I$ body mass index, AJCC American joint Committee on cancer, IDC invasive ductal carcinoma, ILC invasive lobular carcinoma, DCIS ductal carcinoma in situ, ER estrogen receptor, $P R$ progesterone receptor, HER 2 human epidermal-growthfactor receptor 2

activity at post-diagnosis. This suggests that the diagnosis of cancer provided an opportune time to motivate individuals to adopt healthier lifestyle changes, including physical activity $[17,18]$. In this study, we see evidence that a cancer diagnosis was associated with sustained improvement in physical activity for at least 5 years after diagnosis. However, the proportion of women that met the exercise recommendations was still relatively low after cancer diagnosis. Additionally, multivariate analysis showed that marital status, employment status and comorbidities were associated with significant magnitude of change in level of physical activity between pre- and post-diagnosis.

There have been several qualitative studies, which showed that between 16 and 32\% of patients increased their exercise level after diagnosis [33-35]. The proportion of patients who increased exercise after diagnosis was relatively 
Table 2 Comparison of level of physical activity across four study time-points

\begin{tabular}{lllllll}
\hline Level of recreational physical activity & T0 & T1 & T2 & T3 & Mean of T1,2,3 & $\boldsymbol{P}_{\text {To vs mean of T1,2,3 }}$ \\
\hline $\begin{array}{l}\text { MET-hours/week, mean } \pm \text { SD } \\
\text { Physical activity group, } \mathrm{n}(\%)\end{array}$ & $5.9 \pm 11.2$ & $9.9 \pm 13.0$ & $9.8 \pm 14.2$ & $9.3 \pm 14.4$ & $9.6 \pm 11.6$ & \\
$\quad$ & & & & & \\
$\quad$ No exercise & $473(46.4)$ & $209(20.5)$ & $298(29.2)$ & $340(33.4)$ & $111(10.9)$ \\
Low-exercise-level group & $335(32.9)$ & $465(45.6)$ & $397(39.0)$ & $376(36.9)$ & $550(54.0)$ \\
$\quad$ High-exercise-level group & $211(20.7)$ & $345(33.9)$ & $324(31.8)$ & $303(29.7)$ & $358(35.1)$ \\
\hline
\end{tabular}

Abbreviations: MET metabolic equivalent of task, SD standard deviation

higher in this study, at $48.2 \%$. In addition, a few prospective studies had quantitatively compared the physical activity level before and after breast cancer diagnosis in Western population, but the majority of these studies compared physical activity level during a relative short time-window, for instance, from the year before breast cancer diagnosis to 6 or 12-month following cancer diagnosis [19, 21-23, 36]. These studies suggested that compared to pre-diagnosis, patients significantly decreased their level of exercise during active adjuvant treatment. One the other hand, in a German study that included 229 breast cancer patients, the change in physical activity before diagnosis and 14 months after diagnosis was assessed. The investigators reported that $46.1 \%$ of the patients spent more time on physical activity after diagnosis, with an increase from 2.2 to $2.9 \mathrm{~h} /$ week. With a more protracted follow-up, findings from the present study demonstrated that the level of physical activity was higher at 18-month follow-up compared to prediagnosis of cancer, and such increase was sustained at 36months and 60-months follow-up. Up to now, only one study has investigated the change of physical activity over a more protracted period, from 2-year before diagnosis to 30month after diagnosis, and this was conducted among women with breast cancer in the US [25]. Relative to prediagnosis, the average level of physical activity decreased by $50 \%$ in the first 12 months after diagnosis; this gradually recovered at 19-30 months after diagnosis, but still remained about 3 MET-hours/week lower than the level at prediagnosis [25]. Possible reasons for the differences observed between the aforementioned study and the current study may be related to different level of physical activity at prediagnosis. The mean level of physical activity ranges from 13 to 18.8 MET-hours/week in the US and Belgium studies, $[22,25]$ which was higher than the corresponding figure in the present study (median value of 0.6 MET-hours/week). Taken together, all these evidences suggested that during short-term follow-up, patients who were still on active adjuvant treatment did not increase their level of physical activity. As follow-up time became longer, patients would have completed most adjuvant treatment (except for endocrine therapy) and this paralleled the gradually increase in their level of physical activity.

Several studies have examined the factors which could predict the changes of physical activity before and after cancer diagnosis $[19,23,25]$. The association between BMI and changes in physical activity has not been welldefined: two studies reported that obese and overweight women had greater decrease in physical activity after diagnosis relative to normal weight women, $[19,23,25]$ while another study showed that patients who were underweight or had normal BMI had greater reductions in physical activity. ${ }^{50}$ This study showed that patients with higher BMI had a trend in lower increase of physical activity at post-diagnosis. On the other hand, obese women were unlikely to change into high level of physical activity compared to underweight women; this suggests that healthcare professionals may need to pay more attention in counselling overweight and obese patients. Results from multivariate analysis in the present study found that women in relationship had a higher increase in the level of physical activity compared with women who were not in relationship. This phenomenon has also been reported in a previous study, which suggested that marital status was an important determinant for physical activity participation among older adults [37]. In addition, patients who were not employed had higher increase in physical activity than full-time working women, which may be explained by non-working ones having more leisure time. Furthermore, in support to the present finding, Troeschel et al. have reported that each additional comorbidity was associated with a $26 \%$ increase in odds of inactivity [38]..

In recent decades, the improvement in cancer diagnostics, treatment and clinical care have contributed to improved survival of breast cancer patients. However, at the same frame, patients could face long-term side effects of treatment and hence they have various rehabilitation needs. A systematic review which used comprehensive approach to retrieve literature and aimed to investigate the effects of rehabilitation interventions in post-treatment breast cancer patients, supported the benefit of exercise interventions, and showed that exercise could improve outcomes such as shoulder mobility, lymphoedema, pain, fatigue and quality of life [39]. Additionally, physical activity also have several other well-known benefits, including prevention of chronic disease and weight management [40]. These benefits are important for breast cancer survivors who are at higher risk of developing second primary 
Table 3 Changes from no or low to high level of exercise group for individual patient by baseline socio-demographic and clinical factors

\begin{tabular}{|c|c|c|c|c|}
\hline Characteristics & $\mathrm{N}$ & $\%$ & Changes from no or low to high exercise group, $\mathrm{n}(\%)$ & $P$ value \\
\hline Total & 1019 & 100.0 & $211(20.7)$ & \\
\hline Age at diagnosis, year & & & & 0.068 \\
\hline$<40$ & 92 & 9.0 & $13(14.1)$ & \\
\hline $40-49$ & 329 & 32.3 & $78(23.7)$ & \\
\hline $50-59$ & 394 & 38.7 & $87(22.1)$ & \\
\hline$\geq 60$ & 204 & 20.0 & $33(16.3)$ & \\
\hline Education & & & & 0.954 \\
\hline High school or below & 868 & 85.2 & $161(20.7)$ & \\
\hline Collage or above & 151 & 14.8 & $50(20.5)$ & \\
\hline Marital status & & & & 0.079 \\
\hline Married or cohabitating & 728 & 71.4 & $2.7(22.1)$ & \\
\hline Unmarried or divorced or widowed & 291 & 28.6 & $1.3(17.2)$ & \\
\hline Household income, HKD/month & & & & 0.177 \\
\hline$<15,000$ & 463 & 45.4 & $92(29.9)$ & \\
\hline $15,000-30,000$ & 326 & 32.0 & $64(19.6)$ & \\
\hline $30,000-50,000$ & 151 & 14.8 & $31(20.5)$ & \\
\hline$\geq 50,000$ & 79 & 7.8 & $24(30.4)$ & \\
\hline Employment status & & & & 0.472 \\
\hline Full time & 378 & 37.1 & $77(20.4)$ & \\
\hline Part time & 129 & 12.7 & $22(17.1)$ & \\
\hline Not working & 512 & 50.2 & $112(21.9)$ & \\
\hline Menopausal status & & & & 0.055 \\
\hline Premenopausal & 539 & 52.9 & $124(23.0)$ & \\
\hline Postmenopausal & 480 & 47.1 & $87(18.1)$ & \\
\hline BMl at diagnosis, $\mathrm{kg} / \mathrm{m}^{2}$ & & & & 0.007 \\
\hline Underweight $(<18.5)$ & 37 & 3.6 & $9(24.3)$ & \\
\hline Normal (18.5-22.9) & 488 & 47.9 & $108(22.1)$ & \\
\hline Overweight (23-24.9) & 209 & 20.5 & $54(25.8)$ & \\
\hline Obese ( $\geq 25)$ & 285 & 28.0 & $40(14.0)$ & \\
\hline Number of comorbidities & & & & 0.163 \\
\hline None & 629 & 61.7 & $144(22.9)$ & \\
\hline 1 & 259 & 25.4 & $46(17.8)$ & \\
\hline 2 & 101 & 9.9 & $17(16.8)$ & \\
\hline$\geq 3$ & 30 & 2.9 & $4(13.3)$ & \\
\hline AJCC stage at diagnosis & & & & $0.024^{a}$ \\
\hline $0-1$ & 375 & 36.9 & $61(16.2)$ & \\
\hline$\|$ & 471 & 46.2 & $109(23.1)$ & \\
\hline III & 169 & 16.6 & $41(24.3)$ & \\
\hline Missing & 4 & 0.4 & $0(0)$ & \\
\hline Histology & & & & 0.899 \\
\hline IDC & 858 & 84.2 & $176(20.5)$ & \\
\hline ILC & 31 & 3.0 & $8(25.8)$ & \\
\hline DCIS & 56 & 5.5 & $11(19.6)$ & \\
\hline
\end{tabular}


Table 3 Changes from no or low to high level of exercise group for individual patient by baseline socio-demographic and clinical factors (Continued)

\begin{tabular}{|c|c|c|c|c|}
\hline Characteristics & $\mathrm{N}$ & $\%$ & Changes from no or low to high exercise group, $\mathrm{n}(\%)$ & $P$ value \\
\hline Others & 74 & 7.3 & $16(21.6)$ & \\
\hline ER status & & & & $0.969^{a}$ \\
\hline Positive & 763 & 74.9 & $47(20.2)$ & \\
\hline Negative & 233 & 22.9 & $159(20.8)$ & \\
\hline Missing & 23 & 2.3 & $5(21.7)$ & \\
\hline PR status & & & & $0.952^{\mathrm{a}}$ \\
\hline Positive & 598 & 58.7 & $81(20.5)$ & \\
\hline Negative & 395 & 38.8 & $124(20.7)$ & \\
\hline Missing & 26 & 2.6 & $6(23.1)$ & \\
\hline HER 2 status & & & & $0.832^{\mathrm{a}}$ \\
\hline Positive & 274 & 26.9 & $146(20.1)$ & \\
\hline Negative & 686 & 67.3 & $55(21.3)$ & \\
\hline Missing & 59 & 5.8 & $10(16.9)$ & \\
\hline Surgery & & & & 0.521 \\
\hline Mastectomy & 628 & 61.6 & $126(20.1)$ & \\
\hline Conservation & 391 & 38.4 & $85(21.7)$ & \\
\hline Chemotherapy & & & & 0.034 \\
\hline Yes & 774 & 76.0 & $172(22.2)$ & \\
\hline No & 245 & 24.0 & $39(15.9)$ & \\
\hline Radiotherapy & & & & 0.424 \\
\hline Yes & 721 & 70.8 & $154(21.4)$ & \\
\hline No & 298 & 29.2 & $57(19.1)$ & \\
\hline Endocrine therapy & & & & 0.480 \\
\hline Yes & 777 & 76.3 & $157(20.2)$ & \\
\hline No & 242 & 23.7 & $54(22.3)$ & \\
\hline Smoking status & & & & 0.133 \\
\hline Yes & 11 & 1.1 & $0(0)$ & \\
\hline No & 1008 & 98.9 & $211(20.9)$ & \\
\hline Drinking status & & & & 1.00 \\
\hline Yes & 11 & 1.1 & $3(20.7)$ & \\
\hline No & 1008 & 98.9 & $208(20.7)$ & \\
\hline
\end{tabular}

${ }^{a}$ Missing group did not include in $P$ value test

Abbreviations: HKD Hong Kong dollars, BMI body mass index, AJCC American joint Committee on cancer, IDC invasive ductal carcinoma, ILC invasive lobular carcinoma, DCIS ductal carcinoma in situ, ER estrogen receptor, $P R$ progesterone receptor, HER 2 human epidermal-growth-factor receptor 2

cancer, other chronic illnesses such as cardiovascular disease and diabetes, as well as facing psychological stress of living with a diagnosis of cancer [41-45]. Furthermore, increasing evidence have also shown that physical activity is associated with reduced risk of recurrence and better prognosis for breast cancer [46-53].

The present study has shown that the level of physical activity was significantly increased up to 60 -months postdiagnosis compared to that of pre-diagnosis, while no significant difference was noted between the follow-up assessments at 18-, 36- and 60-months post-diagnosis. This suggested that breast cancer survivors adopted increased physical activity soon after their cancer diagnosis, and such changes were sustained as time went on. As increasing evidence have shown that physical activity is associated with better long-term outcome [46-53] and quality of life [54] in women with breast cancer, healthcare professionals should grasp this important window of opportunity to encourage continued and enhanced physical activity. Follow-up of this cohort would provide important information on whether improved physical activity is associated with health outcomes among Chinese breast cancer 
Table 4 Absolute changes in level of physical activity between pre- and post-diagnosis by baseline socio-demographic and clinical factors

\begin{tabular}{|c|c|c|c|c|}
\hline Characteristics & $N$ & $\%$ & $\begin{array}{l}\text { Changes in MET-hours/week, } \\
\text { mean } \pm \text { SD }\end{array}$ & $P$ value \\
\hline Total & 1019 & 100.0 & $3.7 \pm 12.1$ & \\
\hline Age at diagnosis, year & & & & 0.011 \\
\hline$<40$ & 92 & 9.0 & $4.2 \pm 10.8$ & \\
\hline $40-49$ & 329 & 32.3 & $4.8 \pm 11.2$ & \\
\hline $50-59$ & 394 & 38.7 & $4.0 \pm 12.5$ & \\
\hline$\geq 60$ & 204 & 20.0 & $1.3 \pm 13.2$ & \\
\hline Education & & & & 0.918 \\
\hline High school or below & 868 & 85.2 & $3.7 \pm 12.5$ & \\
\hline Collage or above & 151 & 14.8 & $3.6 \pm 9.5$ & \\
\hline Marital status & & & & 0.006 \\
\hline Married or cohabitating & 728 & 71.4 & $4.3 \pm 12.6$ & \\
\hline Unmarried or divorced or widowed & 291 & 28.6 & $2.2 \pm 10.8$ & \\
\hline Household income, HKD/month & & & & 0.059 \\
\hline$<15,000$ & 463 & 45.4 & $3.2 \pm 12.9$ & \\
\hline $15,000-30,000$ & 326 & 32.0 & $4.2 \pm 11.3$ & \\
\hline $30,000-50,000$ & 151 & 14.8 & $2.6 \pm 12.3$ & \\
\hline$\geq 50,000$ & 79 & 7.8 & $6.7 \pm 10.4$ & \\
\hline Employment status & & & & $<0.001$ \\
\hline Full time & 378 & 37.1 & $2.3 \pm 13.4$ & \\
\hline Part time & 129 & 12.7 & $1.7 \pm 14.2$ & \\
\hline Not working & 512 & 50.2 & $5.2 \pm 10.3$ & \\
\hline Menopausal status & & & & 0.299 \\
\hline Premenopausal & 539 & 52.9 & $4.7 \pm 11.6$ & \\
\hline Postmenopausal & 480 & 47.1 & $2.6 \pm 12.6$ & \\
\hline BMl at diagnosis, $\mathrm{kg} / \mathrm{m}^{2}$ & & & & 0.086 \\
\hline Underweight $(<18.5)$ & 37 & 3.6 & $5.1 \pm 13.5$ & \\
\hline Normal (18.5-22.9) & 488 & 47.9 & $4.1 \pm 12.3$ & \\
\hline Overweight (23-24.9) & 209 & 20.5 & $4.6 \pm 12.1$ & \\
\hline Obese $(\geq 25)$ & 285 & 28.0 & $2.2 \pm 11.6$ & \\
\hline Number of comorbidities & & & & 0.002 \\
\hline None & 629 & 61.7 & $4.8 \pm 12.0$ & \\
\hline 1 & 259 & 25.4 & $2.2 \pm 12.7$ & \\
\hline 2 & 101 & 9.9 & $1.2 \pm 10.8$ & \\
\hline$\geq 3$ & 30 & 2.9 & $1.3 \pm 11.4$ & \\
\hline AJCC stage at diagnosis & & & & $0.352^{a}$ \\
\hline $0-1$ & 375 & 36.9 & $3.2 \pm 11.7$ & \\
\hline$\|$ & 471 & 46.2 & $3.9 \pm 13.1$ & \\
\hline III & 169 & 16.6 & $4.4 \pm 10.3$ & \\
\hline Missing & 4 & 0.4 & $-5.0 \pm 10.3$ & \\
\hline Histology & & & & 0.437 \\
\hline IDC & 858 & 84.2 & $3.6 \pm 12.2$ & \\
\hline ILC & 31 & 3.0 & $6.4 \pm 11.4$ & \\
\hline DCIS & 56 & 5.5 & $2.3 \pm 10.0$ & \\
\hline
\end{tabular}


Table 4 Absolute changes in level of physical activity between pre- and post-diagnosis by baseline socio-demographic and clinical factors (Continued)

\begin{tabular}{|c|c|c|c|c|}
\hline Characteristics & $\mathrm{N}$ & $\%$ & $\begin{array}{l}\text { Changes in MET-hours/week, } \\
\text { mean } \pm \text { SD }\end{array}$ & $P$ value \\
\hline Others & 74 & 7.3 & $4.7 \pm 13.3$ & \\
\hline ER status & & & & $0.394^{a}$ \\
\hline Positive & 763 & 74.9 & $3.8 \pm 11.5$ & \\
\hline Negative & 233 & 22.9 & $3.6 \pm 14.0$ & \\
\hline Missing & 23 & 2.3 & $0.3 \pm 11.4$ & \\
\hline PR status & & & & $0.214^{a}$ \\
\hline Positive & 598 & 58.7 & $4.0 \pm 11.8$ & \\
\hline Negative & 395 & 38.8 & $3.5 \pm 12.6$ & \\
\hline Missing & 26 & 2.6 & $-0.2 \pm 11.8$ & \\
\hline HER 2 status & & & & $0.124^{a}$ \\
\hline Positive & 274 & 26.9 & $3.7 \pm 12.8$ & \\
\hline Negative & 686 & 67.3 & $4.0 \pm 12.1$ & \\
\hline Missing & 59 & 5.8 & $0.6 \pm 9.4$ & \\
\hline Surgery & & & & 0.648 \\
\hline Mastectomy & 628 & 61.6 & $3.8 \pm 13.1$ & \\
\hline Conservation & 391 & 38.4 & $3.5 \pm 10.4$ & \\
\hline Chemotherapy & & & & 0.127 \\
\hline Yes & 774 & 76.0 & $4.0 \pm 12.7$ & \\
\hline No & 245 & 24.0 & $2.7 \pm 10.1$ & \\
\hline Radiotherapy & & & & 0.944 \\
\hline Yes & 721 & 70.8 & $3.7 \pm 11.7$ & \\
\hline No & 298 & 29.2 & $3.7 \pm 13.2$ & \\
\hline Endocrine therapy & & & & 0.789 \\
\hline Yes & 777 & 76.3 & $3.6 \pm 11.2$ & \\
\hline No & 242 & 23.7 & $3.9 \pm 14.6$ & \\
\hline Smoking status & & & & 0.455 \\
\hline Yes & 11 & 1.1 & $1.0 \pm 3.7$ & \\
\hline No & 1008 & 98.9 & $3.7 \pm 12.2$ & \\
\hline Drinking status & & & & 0.866 \\
\hline Yes & 15 & 1.5 & $4.2 \pm 11.6$ & \\
\hline No & 1004 & 98.5 & $3.7 \pm 12.1$ & \\
\hline
\end{tabular}

${ }^{a}$ Missing group did not include in $P$ value test

Abbreviations: MET metabolic equivalent of task, SD standard deviation, HKD Hong Kong dollars, BMI body mass index, AJCC American joint Committee on cancer, $I D C$ invasive ductal carcinoma, ILC invasive lobular carcinoma, DCIS ductal carcinoma in situ, ER estrogen receptor, $P R$ progesterone receptor, $H E R 2$ human epidermal-growth-factor receptor 2

survivors. However, it has to be noted that although most of the patients became more physically active during follow-ups, they still did not reach the recommended level of physical activity.

The strengths of the present study included its large, prospective design, based on the data collected from validated modified Chinese Baecke questionnaire that included measurement of physical activity in doing sports. Furthermore, this study compared physical activity between pre-diagnosis with three time-points after cancer diagnosis, which allows the investigators to understand the relative long-term changes made among breast cancer patients. There are several limitations in this study. Firstly, physical activity was based on self-reported questionnaire, thus overestimation or underestimation was possible. Nevertheless, this potential bias was reduced by the application of the same questionnaire over the four time-points. Objective instruments, such as accelerometer, would be more useful in future studies to monitor physical activity in a more accurate manner. Secondly, the modified Chinese Baeke questionnaire 
included physical activity at work, in doing housework, at leisure time and in doing sports. However, the present study only analyzed the level of physical activity in doing sports. Additionally, the modified Chinese Baecke questionnaire has only been validated in a random sample of Hong Kong Chinese adult population, although not specifically validated in cancer patients. Thirdly, although the majority of the participants included in the current study had stable or improvement in level of physical activity, these findings may not be able to represent the whole breast cancer population in Hong Kong. The present findings should be interpreted with care because there may be a potential selection bias, as patients who were more concerned with health improvement would be those who were more likely to agree to participate in this study. In addition, as sizeable number of patients $(n=443)$ in the whole cohort were not included in this analysis, it may affect the generalization of study results. Moreover, the loss of subjects may contribute to selection bias if those lost to follow up are more or less likely to perform exercise. Fourthly, it has to be acknowledged that the sample size was not estimated for the present analysis. Last but not least, given this study was undertaken in two regional cancer centers, the patients might have adopted different potential lifestyle interventions based on education, counseling, sports groups that were offered in individual center. Hence, the lack of standardization of lifestyle educational intervention could affect the study results.

\section{Conclusions}

The present findings provide important evidence on breast cancer patients' habits on sports activity following their diagnosis. In the present study, significant and long-term increase in post-diagnosis sports activity were observed among Chinese women with breast cancer, which was accord with current lifestyle recommendation from international authorities. However, the proportion of patients who met the recommended exercise level for cancer survivors was still low. These findings provided an insight into the fact that a cancer diagnosis can motivate patients to adopt a healthy lifestyle. Encouraging patients on the importance of durable high level of physical activity in breast cancer survivorship is warranted. In addition, long-term follow-up is needed to provide more evidence on possible association of high physical activity and cancer outcome.

\section{Supplementary information}

Supplementary information accompanies this paper at https://doi.org/10. 1186/s12885-020-07517-6.

Additional file 1 Supplementary Table 1. Modified Chinese Baecke Questionnaire. Supplementary Table 2. Changes in level of physical activity between pre- and post-Changes in level of physical activity between pre- and post-diagnosis for individual patient. Supplementary Table 3. Multivariable logistic regression model assessing changes from no or low to high level of exercise group for individual patient in relation to socio-demographic and clinical factors. Supplementary Table 4. Multivariable linear regression model assessing absolute changes in level of physical activity between pre- and post-diagnosis in relation to sociodemographic and clinical factors.

\section{Abbreviations}

BMI: Body mass index; ACS: American Cancer Society; WCRF/AICR: World Cancer Research Fund/American Institute for Cancer Research; MET: Equivalent of task; BCRL: Breast cancer related lymphedema; AWS: Axillary web syndrome; SD: Standard deviation; HKD: Hong Kong dollars; AJCC: American joint Committee on cancer; IDC: Invasive ductal carcinoma; ILC: Invasive lobular carcinoma; DCIS: Ductal carcinoma in situ; ER: Estrogen receptor; PR: Progesterone receptor; HER 2: Human epidermalgrowth-factor receptor 2

\section{Acknowledgements}

Not Applicable.

\section{Authors' contributions}

YYL, SCH and WY designed the study and performed the statistical analysis. AC, CK, KLC, RL collected data. YYL, SCH and WY wrote the first draft of the manuscript, to which all authors subsequently contributed. All authors read and approved the final manuscript.

\section{Funding}

This study was funded by World Cancer Research Fund International (Grant Number WCRF 2010/249 and WCRF 2014/1197). The funding bodies played no role in the design of the study and collection, analysis, and interpretation of data and in writing the manuscript.

\section{Availability of data and materials}

All analyzed data during the current study were presented in the main manuscript and supplementary file. The original datasets are available from the corresponding author on reasonable request.

\section{Ethics approval and consent to participate}

All procedures performed in studies involving human participants were in accordance with the ethical standards of the Joint CUHK-NTEC Clinical Research Ethics Committee and the KWC Research Ethics Committee of the Chinese University of Hong Kong and the Hong Kong Hospital Authority and with the 1964 Helsinki declaration and its later amendments or comparable ethical standards. Written consent was obtained from all individual participants included in the study. The study was approved by the Joint CUHKNTEC Clinical Research Ethics Committee and the KWC Research Ethics Committee of the Chinese University of Hong Kong and the Hong Kong Hospital Authority.

\section{Consent for publication}

Not Applicable.

\section{Competing interests}

The authors declare that they have no competing interests.

\section{Author details}

${ }^{1}$ Department of Clinical Oncology, Prince of Wales Hospital, the Chinese University of Hong Kong, Shatin, New Territories, Hong Kong SAR, China. ${ }^{2}$ Division of Epidemiology, the Jockey Club School of Public Health and Primary Care, the Chinese University of Hong Kong, New Territories, Hong Kong SAR, China. ${ }^{3}$ Department of Clinical Oncology, Princess Margaret Hospital, Hong Kong SAR, China. ${ }^{4}$ Hong Kong Cancer Institute, State Key Laboratory in Oncology in South China, Faculty of Medicine, the Chinese University of Hong Kong, New Territories, Hong Kong SAR, China.

Received: 10 June 2020 Accepted: 9 October 2020

Published online: 19 October 2020

References

1. Siegel RL, Miller KD, Jemal A. Cancer statistics, 2019. CA Cancer J Clin. 2019; 69(1):7-34. 
2. Overview of Hong Kong Cancer Statistics of 2017. Hong Kong Cancer Registry, Hospital Authority. http://www3.ha.org.hk/cancereg/. Accessed 15 May 2020.

3. Michelotti A, Invernizzi M, Lopez G, Lorenzini D, Nesa F, De Sire A, Fusco N. Tackling the diversity of breast cancer related lymphedema: perspectives on diagnosis, risk assessment, and clinical management. Breast. 2019;44:15-23.

4. de Sire A, Losco L, Cigna E, Lippi L, Gimigliano F, Gennari A, Cisari C, Chen HC, Fusco N, Invernizzi M. Three-dimensional laser scanning as a reliable and reproducible diagnostic tool in breast cancer related lymphedema rehabilitation: a proof-of-principle study. Eur Rev Med Pharmacol Sci. 2020;24(8):4476-85.

5. de Sire A, Losco L, Cisari C, Gennari A, Boldorini R, Fusco N, Cigna E, Invernizzi M. Axillary web syndrome in women after breast cancer surgery referred to an oncological rehabilitation unit: which are the main risk factors? A retrospective case-control study. Eur Rev Med Pharmacol Sci. 2020;24(15):8028-35.

6. de Sire A, Invernizzi M, Lippi L, Cisari C, Özçakar L, Franchignoni F. Blurred lines between axillary web syndrome and Mondor's disease after breast cancer surgery: a case report. Ann Phys Rehabil Med. 2020;63(4):365-7.

7. Thong MSY, van Noorden CJF, Steindorf K, Arndt V. Cancer-related fatigue: causes and current treatment options. Curr Treat Options in Oncol. 2020;21(2):17.

8. Jones JM, Olson K, Catton P, Catton CN, Fleshner NE, Krzyzanowska MK, McCready DR, Wong RK, Jiang H, Howell D. Cancer-related fatigue and associated disability in post-treatment cancer survivors. J Cancer Surviv : Res Pract. 2016;10(1):51-61.

9. Hasenoehrl T, Palma S, Ramazanova D, Kölbl H, Dorner TE, Keilani M, Crevenna R. Resistance exercise and breast cancer-related lymphedema-a systematic review update and meta-analysis. Support Care Cancer. 2020; 28(8):3593-603.

10. Juvet LK, Thune I, Elvsaas I, Fors EA, Lundgren S, Bertheussen G, Leivseth $G$, Oldervoll LM. The effect of exercise on fatigue and physical functioning in breast cancer patients during and after treatment and at 6 months followup: a meta-analysis. Breast. 2017;33:166-77.

11. Del-Rosal-Jurado A, Romero-Galisteo R, Trinidad-Fernández M, GonzálezSánchez M, Cuesta-Vargas A, Ruiz-Muñoz M. Therapeutic physical exercise post-treatment in breast cancer: a systematic review of clinical practice guidelines. J Clin Med. 2020;9(4):1239.

12. Runowicz CD, Leach CR, Henry NL, Henry KS, Mackey HT, Cowens-Alvarado RL, Cannady RS, Pratt-Chapman ML, Edge SB, Jacobs LA, et al. American cancer society/American society of clinical oncology breast cancer survivorship care guideline. J Clin Oncol. 2016;34(6):611-35.

13. Rock CL, Doyle C, Demark-Wahnefried W, Meyerhardt J, Courneya KS, Schwartz AL, Bandera EV, Hamilton KK, Grant B, McCullough M, et al. Nutrition and physical activity guidelines for cancer survivors. CA Cancer J Clin. 2012;62(4):243-74.

14. World Cancer Research Fund/American Institute for Cancer Research. Food, nutrition, physical activity, and the prevention of cancer: a global perspective. Washington, DC: AICR; 2007.

15. Blanchard CM, Courneya KS, Stein K, American Cancer Society's SCS, II. Cancer survivors' adherence to lifestyle behavior recommendations and associations with health-related quality of life: results from the American Cancer Society's SCS-II. J Clin Oncol. 2008;26(13):2198-204.

16. Inoue-Choi M, Lazovich D, Prizment AE, Robien K. Adherence to the World Cancer Research Fund/American Institute for Cancer Research recommendations for cancer prevention is associated with better healthrelated quality of life among elderly female cancer survivors. J Clin Oncol. 2013;31(14):1758-66.

17. Demark-Wahnefried W, Aziz NM, Rowland JH, Pinto BM. Riding the crest of the teachable moment: promoting long-term health after the diagnosis of cancer. J Clin Oncol. 2005;23(24):5814-30.

18. Humpel $\mathrm{N}$, Magee $\mathrm{C}$, Jones SC. The impact of a cancer diagnosis on the health behaviors of cancer survivors and their family and friends. Support Care Cancer. 2007;15(6):621-30

19. Irwin ML, Crumley D, MCTiernan A, Bernstein L, Baumgartner R, Gilliland FD, Kriska A, Ballard-Barbash R. Physical activity levels before and after a diagnosis of breast carcinoma: the Health, Eating, Activity, and Lifestyle (HEAL) study. Cancer. 2003;97(7):1746-57.

20. Irwin ML, McTiernan A, Bernstein L, Gilliland FD, Baumgartner R, Baumgartner K, Ballard-Barbash R. Physical activity levels among breast cancer survivors. Med Sci Sports Exerc. 2004;36(9):1484-91.

21. Andrykowski MA, Beacham AO, Jacobsen PB. Prospective, longitudinal study of leisure-time exercise in women with early-stage breast cancer. Cancer Epidemiol, Biomarkers Prev. 2007;16(3):430-8.
22. Devoogdt N, Van Kampen M, Geraerts I, Coremans T, Fieuws S, Lefevre J, Philippaerts R, Truijen S, Neven P, Christiaens MR. Physical activity levels after treatment for breast cancer: one-year follow-up. Breast Cancer Res Treat. 2010;123(2):417-25.

23. Kwan ML, Sternfeld B, Ergas IJ, Timperi AW, Roh JM, Hong CC, Quesenberry CP, Kushi LH. Change in physical activity during active treatment in a prospective study of breast cancer survivors. Breast Cancer Res Treat. 2012; 131(2):679-90.

24. Johnsson A, Johnsson A, Johansson K. Physical activity during and after adjuvant chemotherapy in patients with breast cancer. Physiotherapy. 2013; 99(3):221-7.

25. Littman AJ, Tang MT, Rossing MA. Longitudinal study of recreational physical activity in breast cancer survivors. J Cancer surviv : Res Pract. 2010; 4(2):119-27.

26. Lei YY, Ho SC, Cheng A, Kwok C, Cheung KL, He YQ, Lee Cl, Lee R, Yeo W. Dietary changes in the first 3 years after breast cancer diagnosis: a prospective Chinese breast cancer cohort study. Cancer Manag Res. 2018;10:4073-84.

27. Edge SB, Byrd DR, Compton CC, Fritz AG, Greene FL, Trotti A. AJCC cancer staging manual. 7th ed. New York: Springer; 2010.

28. WHO/IASO/IOTF. The Asia-Pacific perspective: redefining obesity and its treatment. Melbourne: Health Communications Australia; 2000.

29. Ho SC, Yu R, Chan S. Comparison of the modified Chinese Baecke Questionnaire with a 3-day activity diary in a Hong Kong Chinese population. Asia-Pac J Public Health. 2015;27(2):Np2358-71.

30. Ainsworth BE, Haskell WL, Herrmann SD, Meckes N, Bassett DR Jr, TudorLocke C, Greer JL, Vezina J, Whitt-Glover MC, Leon AS. 2011 compendium of physical activities: a second update of codes and MET values. Med Sci Sports Exerc. 2011;43(8):1575-81.

31. Pate RR, Pratt M, Blair SN, Haskell WL, Macera CA, Bouchard C, Buchner D, Ettinger W, Heath GW, King AC, et al. Physical activity and public health. A recommendation from the Centers for Disease Control and Prevention and the American College of Sports Medicine. Jama. 1995;273(5):402-7.

32. Shu XO, Zheng Y, Cai H, Gu K, Chen Z, Zheng W, Lu W. Soy food intake and breast cancer survival. Jama. 2009;302(22):2437-43.

33. Blanchard CM, Denniston MM, Baker F, Ainsworth SR, Courneya KS, Hann DM, Gesme DH, Reding D, Flynn T, Kennedy JS. Do adults change their lifestyle behaviors after a cancer diagnosis? Am J Health Behav. 2003;27(3):246-56.

34. Patterson RE, Neuhouser ML, Hedderson MM, Schwartz SM, Standish L, Bowen DJ. Changes in diet, physical activity, and supplement use among adults diagnosed with cancer. J Am Diet Assoc. 2003;103(3):323-8.

35. Alfano CM, Day JM, Katz ML, Herndon JE 2nd, Bittoni MA, Oliveri JM, Donohue K, Paskett ED. Exercise and dietary change after diagnosis and cancer-related symptoms in long-term survivors of breast cancer: CALGB 79804. Psychooncology. 2009;18(2):128-33.

36. Huy C, Schmidt ME, Vrieling A, Chang-Claude J, Steindorf K. Physical activity in a German breast cancer patient cohort: one-year trends and characteristics associated with change in activity level. Eur J Cancer. 2012;48(3):297-304.

37. Pettee KK, Brach JS, Kriska AM, Boudreau R, Richardson CR, Colbert LH, Satterfield S, Visser M, Harris TB, Ayonayon HN, et al. Influence of marital status on physical activity levels among older adults. Med Sci Sports Exerc. 2006;38(3):541-6.

38. Troeschel AN, Leach CR, Shuval K, Stein KD, Patel AV. Physical activity in cancer survivors during "re-entry" following cancer treatment. Prev Chronic Dis. 2018;15:E65.

39. Olsson Möller U, Beck I, Rydén L, Malmström M. A comprehensive approach to rehabilitation interventions following breast cancer treatment - a systematic review of systematic reviews. BMC Cancer. 2019;19(1):472.

40. Haskell WL, Lee IM, Pate RR, Powell KE, Blair SN, Franklin BA, Macera CA, Heath GW, Thompson PD, Bauman A. Physical activity and public health: updated recommendation for adults from the American College of Sports Medicine and the American Heart Association. Med Sci Sports Exerc. 2007;39(8):1423-34.

41. Molina-Montes E, Requena M, Sanchez-Cantalejo E, Fernandez MF, ArroyoMorales M, Espin J, Arrebola JP, Sanchez MJ. Risk of second cancers cancer after a first primary breast cancer: a systematic review and meta-analysis. Gynecol Oncol. 2015;136(1):158-71.

42. Gernaat SAM, Ho PJ, Rijnberg N, Emaus MJ, Baak LM, Hartman M, Grobbee DE, Verkooijen HM. Risk of death from cardiovascular disease following breast cancer: a systematic review. Breast Cancer Res Treat. 2017;164(3):537-55.

43. Hooning MJ, Botma A, Aleman BM, Baaijens MH, Bartelink H, Klijn JG, Taylor CW, van Leeuwen FE. Long-term risk of cardiovascular disease in 10-year survivors of breast cancer. J Natl Cancer Inst. 2007;99(5):365-75. 
44. Lipscombe LL, Chan WW, Yun L, Austin PC, Anderson GM, Rochon PA. Incidence of diabetes among postmenopausal breast cancer survivors. Diabetologia. 2013;56(3):476-83.

45. Burgess C, Cornelius V, Love S, Graham J, Richards M, Ramirez A. Depression and anxiety in women with early breast cancer: five year observational cohort study. Bmj. 2005;330(7493):702.

46. Holick CN, Newcomb PA, Trentham-Dietz A, Titus-Ernstoff L, Bersch AJ, Stampfer MJ, Baron JA, Egan KM, Willett WC. Physical activity and survival after diagnosis of invasive breast cancer. Cancer Epidemiol, Biomark Prev. 2008;17(2):379-86.

47. Irwin ML, Smith AW, McTiernan A, Ballard-Barbash R, Cronin K, Gilliland FD, Baumgartner RN, Baumgartner KB, Bernstein L. Influence of pre- and postdiagnosis physical activity on mortality in breast cancer survivors: the health, eating, activity, and lifestyle study. J Clin Oncol. 2008;26(24):3958-64.

48. Sternfeld B, Weltzien E, Quesenberry CP Jr, Castillo AL, Kwan M, Slattery ML, Caan BJ. Physical activity and risk of recurrence and mortality in breast cancer survivors: findings from the LACE study. Cancer Epidemiol, Biomark Prev. 2009;18(1):87-95.

49. Bertram LA, Stefanick ML, Saquib N, Natarajan L, Patterson RE, Bardwell W, Flatt SW, Newman VA, Rock CL, Thomson CA, et al. Physical activity, additional breast cancer events, and mortality among early-stage breast cancer survivors: findings from the WHEL study. Cancer Causes Control. 2011;22(3):427-35.

50. Chen X, Lu W, Zheng W, Gu K, Matthews CE, Chen Z, Zheng Y, Shu XO. Exercise after diagnosis of breast cancer in association with survival. Cancer Prev Res (Phila). 2011;4(9):1409-18.

51. Ibrahim EM, Al-Homaidh A. Physical activity and survival after breast cancer diagnosis: meta-analysis of published studies. Med Oncol. 2011:28(3):753-65.

52. Irwin ML, McTiernan A, Manson JE, Thomson CA, Sternfeld B, Stefanick ML, Wactawski-Wende J, Craft L, Lane D, Martin LW, et al. Physical activity and survival in postmenopausal women with breast cancer: results from the women's health initiative. Cancer Prev Res (Phila). 2011;4(4):522-9.

53. Holmes MD, Chen WY, Feskanich D, Kroenke CH, Colditz GA. Physical activity and survival after breast cancer diagnosis. Jama. 2005;293(20):2479-86.

54. Mandelblatt JS, Luta G, Kwan ML, Makgoeng SB, Ergas IJ, Roh JM, Sternfeld B, Adams-Campbell LL, Kushi LH. Associations of physical activity with quality of life and functional ability in breast cancer patients during active adjuvant treatment: the pathways study. Breast Cancer Res Treat. 2011;129(2):521-9.

\section{Publisher's Note}

Springer Nature remains neutral with regard to jurisdictional claims in published maps and institutional affiliations.

Ready to submit your research? Choose BMC and benefit from:

- fast, convenient online submission

- thorough peer review by experienced researchers in your field

- rapid publication on acceptance

- support for research data, including large and complex data types

- gold Open Access which fosters wider collaboration and increased citations

- maximum visibility for your research: over $100 \mathrm{M}$ website views per year

At $\mathrm{BMC}$, research is always in progress.

Learn more biomedcentral.com/submissions 